\title{
Review of torque models for offshore helical piles
}

\author{
Giovanni Spagnoli ${ }^{1, *}$, and Cristina de Hollanda Cavalcanti Tsuha ${ }^{2}$ \\ ${ }^{1}$ MBCC Group, 83308 Trostberg, Germany \\ ${ }^{2}$ Department of Geotechnical Engineering, University of São Paulo, 13566-590 São Carlos, Brazil
}

\begin{abstract}
Helical (or screw) piles, sometimes defined as anchors, are a piled system consisting of one or multiple helices welded along the shaft. Piles are installed by applying a torque to the shaft. The pile is rotated into the soil and the rate of advancement should be an amount equal to the pitch for each rotation in order to minimize the disturbance of the original soil. Torque is maybe the most important parameter to be assessed during pile installation. In fact, torque and uplift capacity are directly proportional. Generally, torque depends on the soil conditions and on the geometrical features of the pile. Torque increases with sand density, installation depth, friction angle of sand, pile shaft and helix diameters. The geometry of the pile has a strong influence on the torque, the larger the helix-to-shaft ratio is, the larger the torque will be. In offshore applications helical piles are being considered as a valid alternative. However, one of the issues is still related to the assessment of the installation torque values. Several torque models have been considered and critical evaluated. Some simple comparisons among selected torque models have been also done and discussed.
\end{abstract}

\section{Introduction}

For offshore structures, both for oil \& gas and renewable energies, driven and sometimes drilled piles are the most used foundation type [1-3].

In the offshore environment piles are often subjected to uplifting forces [4-5]. Besides, many offshore structures require foundations-anchors with a significant tension capacity, such as tension-leg platforms [2], tension-leg floating wind turbines [6], wind turbines founded on tripod [7] or jacket [8] structures, converting moment at the base of the turbine into a push/pull loading applied to the foundations [9]. As large-diameter helical piles (also known as screw piles) can develop large tension capacity, they can be employed as an alternative to driven steel tubular piles to support these structures [10]. Helical (screw) piles are a valid form of foundations and they have been successfully used in different ground conditions including marine environments [11-12]. They are installed into the soil by applying a torque to the upper end of the shaft by mechanical means [13]. Helical piles are made by high strength steel and are composed of an open or closed end-pipe and a helix (or multiple helices) welded at the pipe end [10] (see Fig. 1).

Helical piles have been suggested as a potential alternative to driven piles as offshore pile [7, 14-17], because they provide a large uplift capacity due to the anchor effect of the helix; they do not produce any backflow, muddy water, or waste materials at all; and they have excellent pile bending capacity, strength, and seismic performance. Helical piles consist of a helix, $D$, with a pitch $p$, and a shaft, $d$. They can be open or closed-end.

According to [13], the uplift capacity of helical piles is proportional to the torsional resistance to the pile penetration measured at the end of installation, and the installation effort is used as a tool to evaluate foundation quality. Similarly, [18] state that the average installation torque is related to the compressive and uplift capacities.

The geometry of the pile has a strong influence on the installation torque, the larger the wing ratio is, the larger the torque will be [12]. Torque assessment is, therefore, very important in offshore operations as it is directly dependent on the site condition, pile geometry and the design depth estimated for reaching the necessary load capacities (in tension and compression) [19-20]. This paper shows different torque models proposed in the past and calculation examples are performed considering a pile geometry and geotechnical conditions to show the different results obtained.

\section{Torque models}

Helical foundation and anchor capacity in uplift have been empirically related to installation torque [21-22]:

$$
Q=K_{t} T
$$

where $Q$ is the uplift capacity of a screw pile, $K_{t}$ is the empirical torque factor, and $T$ is the average installation torque over the final distance of penetration equal to three time the largest blade diameter if more than one helix is used. According to [21], the empirical value of

\footnotetext{
* Corresponding author: giovanni.spagnoli@mbcc-group.com
} 
the $K_{t}$ factor decreases with increasing the pile shaft diameter.

The prediction of the uplift behavior of helical piles is very complex as determination of stress-strain parameters for the disturbed soil (by the installation process) to calculate pile displacement during pull-out loading is not an easy task [23]. Assessing the torque value during the installation is not an easy operation. Theoretically, the screw pile penetrates while rotating by the pitch amount [24].

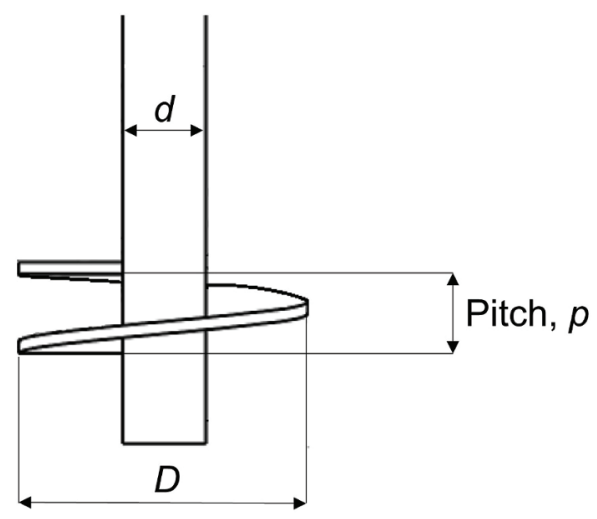

Fig. 1. Sketch of a single-helix pile with a helix diameter, $D$, pitch, $p$, and shaft diameter, $d$.

\subsection{Ghaly and Hanna model}

[25] developed a theoretical method to estimate the installation torque of helical piles in sand based on the system of forces generated on the screw blades and shaft when the pile penetrated the soil by rotation. The authors mentioned that the performance of helical piles during installation is influenced by several factors, such as: plate diameter, helix pitch and angle, shaft diameter, general configuration (single-helix, multi-uniform helices, multi-tapered helices, helices with variable angle, etc.), thickness and shape of cutting edge of the screw plates, method used in manufacturing the helical pile (bolted, welded, etc.), pile material and roughness, and pile's end (conical or flat). The model proposed by [25] to estimate the required installation torque of a single helix anchor in sand is given by the following equation:

$$
T=T_{1}+T_{2}+T_{3}+T_{4}+T_{5}+T_{6}+T_{7}
$$

where $T_{1}$ is the resisting moment on the pile's shaft; $T_{2}$ and $T_{3}$ are resisting moments acting on the helix; $T_{4}$ and $T_{5}$ are the resisting moments acting on the upper and lower surfaces of the helix, due to the active and passive earth pressures; $T_{6}$ is the resisting moment due to the force acting on the entire height of the helix pitch; and $T_{7}$ is the resisting moment acting on the perimeter of the thickness of the helix. Details about the resisting moments can be found in [25]. Additionally, the model considers the unit weight of sand $\gamma$, the installation depth of the helix, $H$, the soil/pile friction angle, $\delta$, the coefficient of friction between pile material and soil, $K_{f}=\tan \delta$, the helix angle, $\psi$, the pitch, p, the helix thickness, $\mathrm{t}$, the outer helix diameter, $D$, the top surface area of the helix, $A_{t}$, the inner helix diameter, $D_{0}$, the shaft diameter, $d$, the coefficient of active and passive earth pressure, respectively $K_{a}$ and $K_{p}$, the soil friction angle, $\phi$, and the modified coefficient of passive earth pressure, $K_{p}^{\prime}=0.3 K_{p}$, to consider the installation effects. The value of modified coefficient $K_{p}^{\prime}$ was obtained from measurements of stress transducers located around the installation path.

\subsection{Sakr model}

[26] proposed a theoretical model to estimate the installation torque of helical piles in cohesionless soils. The model is very similar to the method proposed in [25], described above. The two main differences between the models are:

- [26] utilizes the effective stresses approach, while the model of [25] is based on total stresses approach; - [25] used a reduced coefficient of passive earth pressure $\left(K_{p}^{\prime}=0.3 K_{p}\right)$, whereas [26] does not reduce the value of $K_{p}$ in his model.

[26] considers numerous factors affecting resisting moments to helical pile installation (or installation torque) including pile configuration and soil properties. Unlike [25] model, [26] considers the bearing capacity factor of Terzaghi, $N_{q}$, for obtaining the torque value. This factor depends on the mechanical properties of the soil and installation method of the pile.

\subsection{Spagnoli model}

[10] presented some modifications on the model proposed by [27], which was developed to estimate the installation torque using CPT data. He used the original equation presented in [13], eq. [3], to correlate installation torque and uplift capacity of single-helix piles in sand:

$$
T=\left[Q_{s} d / 2\right]+\left[Q_{h} d_{c} \tan \left(\theta+\delta_{r}\right) / 2\right]
$$

where $d_{c}$ is diameter of a circle corresponding to the helix surface area and $\theta$ is the helix angle. The values of $d_{c}$ and $\theta$ can be calculated by:

$$
\begin{aligned}
& d_{c}=2 / 3\left(D^{3}-d^{3} / D^{2}-d^{2}\right) \\
& \theta=\tan ^{-1}\left(p / \pi d_{c}\right)
\end{aligned}
$$

where $d$ is the shaft external diameter, and $p$ is the helix pitch. The equation [3] was evaluated in [13] by centrifuge model tests in dry sand, using measurements of installation torque and uplift capacity of helical piles with different geometries, and a good agreement between measured and predicted results was observed. For the estimation of installation torque, [10] substituted the values of $Q_{s}$ and $Q_{h}$ (shaft resistance and helix uplift bearing capacity) in equation [3] from the model of [27] by the following expressions:

$$
Q_{s}=q_{s a v} \pi d L
$$




$$
Q_{h}=q_{u p} \pi\left(D^{2}-d^{2}\right) / 4
$$

\subsection{Other models}

[28] presented a CPT based design procedure for the prediction of installation torque of helical piles installed in sand. The required torque to install a helical pile is the sum of the shaft $\left(T_{s}\right)$, the base frictional resistance $\left(T_{b}\right)$, and the torque exerted due to helix resistance $\left(T_{h}\right)$.

[29] adapted the model presented in [13] for a single helix pile. [13] only related the final installation torque to the measured uplift capacity (as shown in equation [3]) and no equation was proposed by them to estimate the pile uplift capacity. [29] improved the model of [13] by including $Q_{s}$ and $Q_{h}$ (shaft and helix uplift bearing resistance) estimated by the following equations:

$$
\begin{aligned}
& Q_{s}=q_{s} \pi d L \\
& Q_{h}=A_{h}\left(H \gamma^{\prime} F_{q}\right)
\end{aligned}
$$

where $q_{s}$ is the average unit shaft friction of soil $\left(q_{s}\right.$ $=\sigma^{\prime}{ }_{v} K_{p}$ tan $\delta$, where $K_{p}$, is the modified coefficient of passive earth pressure (suggested in [25] for single-helix anchors in sand), $A_{h}$ is projected helix area, and $F_{q}$ is the breakout factor for helical anchors in sand proposed in [30].

The method of Spagnoli et al. [29], similarly to the models suggested in [25] and in [26], correlates the installation torque with soil and interface steel-soil parameters. Therefore, to utilize these methods using the results of in-situ soil tests (SPT or CPT), it is necessary to use empirical correlations to estimate the values of the soil parameters.

For the estimation of installation torque, among the models shown previously, three different theoretical models proposed to calculate the final installation torque of helical piles in non-cohesive soils were used [25, 26, and 29]. The calculations are performed considering one helix with a constant blade thickness of $0.0254 \mathrm{~m}$, with $D$ and $d$ of 0.6 and $0.3 \mathrm{~m}$ respectively and $p$ being $1 / 3$ of $D$. An effective unit weight of $10 \mathrm{kN} / \mathrm{m}^{3}$ has been chosen, as constant revolution per meter (RPM) values of 20 . As interface friction angle values, we used the critical interface friction angle value, $\delta_{c v}$ of $29^{\circ}$ suggested in [31] for fine sand-steel interfaces. The critical interface friction angle is more appropriate to simulate the helical pile installation (under motion condition and large relative displacements).

Torque values for three different soil friction angle values, $\phi$, namely $29^{\circ}, 32^{\circ}$ and $35^{\circ}$ over an embedment depth of $75 \mathrm{~m}$ have been considered (Figs 2 to 4 ). This brief parametric analysis has been conducted to observe which geotechnical and geometrical parameter influence the installation power of the helical pile to a great extent.

\section{Assessment of installation power}

Installation power, $P$, is also considered. $P$ is the energy absorbed in the unit of time. $P$ is an interesting parameter because it permits to know the specifications required of the machine to install a pile in a soil with different geotechnical properties. The values of power are given by following equation:

$$
\begin{gathered}
P=P(T)+P(V)=T(\omega)+V(\omega / 2 \pi) p \\
v=(\omega / 2 \pi) p
\end{gathered}
$$

where $P(T)$ is the power due to the torque, $P(V)$ is the power due to the vertical force, $v$ is the advancement of the helical pile (in $\mathrm{m} / \mathrm{sec}$ ) into the soil at a constant penetration rate equal to pitch size, $p$, and $\omega$ represents the angular velocity. Among the works mentioned above, only [25] presented an equation to estimate the magnitude of the downward vertical force $(V)$ required to overcome the forces acting against the downward motion. Therefore, to estimate the installation power in the current paper, the crowd force applied on the pile during installation (to maintain advancement of the helical pile into the soil at constant penetration rate equal to pitch size per RPM) can be given by the following equations [25]:

$$
V=\sum V_{i}
$$

The models of [25, 26, and 29] have been used because they are easily comparable among each other. Besides, the input parameters can also be adjusted to employ them for real in situ tests. Even though the methods are easily comparable among each other, they also analyse the parameters from several points of view because each of these methods were evaluated under different conditions.

The [26] method was compared with field results. The $[25,29]$ presented good agreement with measured results from centrifuge model tests in dry sand [29].

It is also important to understand what is the induced shear stress which the pile can resist. This is given by (see [32]):

$$
\tau_{\max }=2 T r_{\text {ext }} / \pi\left(r^{4}{ }_{\text {ext }}-r^{4}{ }_{\text {int }}\right)
$$

To verify the yield strength of steel, we need to use the Tresca's criterion:

$$
\sigma_{i d, \max }=\sqrt{ }(V / A)^{2}+3 \tau_{\max }^{2}
$$

where $\sigma_{i d, \max }$ is the maximum ideal stress on the external ring of the pile at the surface (where stress condition is critical), which has to be compared with the yield strength of the pile, $V$ is the vertical force; A is the plan cross sectional area of the pile, i.e. $A=\pi\left(r^{2} e_{e x t} r^{2}{ }_{i n t}\right)$. Considering the A36 steel for the pile, its yield strength is $250 \mathrm{MPa}$, with an ultimate tensile strength of $400-550$ $\mathrm{MPa}$ and a density of $7.8 \mathrm{~g} / \mathrm{cm}^{3}$. None of the piles installed under the conditions shown in Tab. 1 fulfils the requirement, hence the pile fails to resist the torque needed for the installation.

\section{Results and discussion}

\subsection{Installation torque and power}

Fig. 2 shows the results with the model of [25]. The torque values at $25 \mathrm{~m}$ depth increase from $0.92 \mathrm{MNm}$ for 
$29^{\circ}$ friction angle, to 1.10 and $1.31 \mathrm{MNm}$ for $32^{\circ}$ and $35^{\circ}$ respectively. Fig. 3 shows the results with the model of [26]. The torque values at $25 \mathrm{~m}$ depth increase from 2.87 $\mathrm{MNm}$ for $29^{\circ}$ friction angle, to 3.25 and $3.69 \mathrm{MNm}$ for $32^{\circ}$ and $35^{\circ}$ respectively. Fig. 4 shows the results with the model of [29]. The torque values at $25 \mathrm{~m}$ depth increase from $0.45 \mathrm{MNm}$ for $29^{\circ}$ friction angle, to 0.48 and $0.51 \mathrm{MNm}$ for $32^{\circ}$ and $35^{\circ}$ respectively.

The estimated torque results shown in Figs. 2 to 4 illustrate that the model of [26] provided higher values in comparison to the other two models. For a pile installed at $25 \mathrm{~m}$ depth in saturated sand with friction angle of $32^{\circ}$, the torque values estimated using the model [26] were approximately 3 and 7 times the values obtained using the model of [25] and [29] respectively.

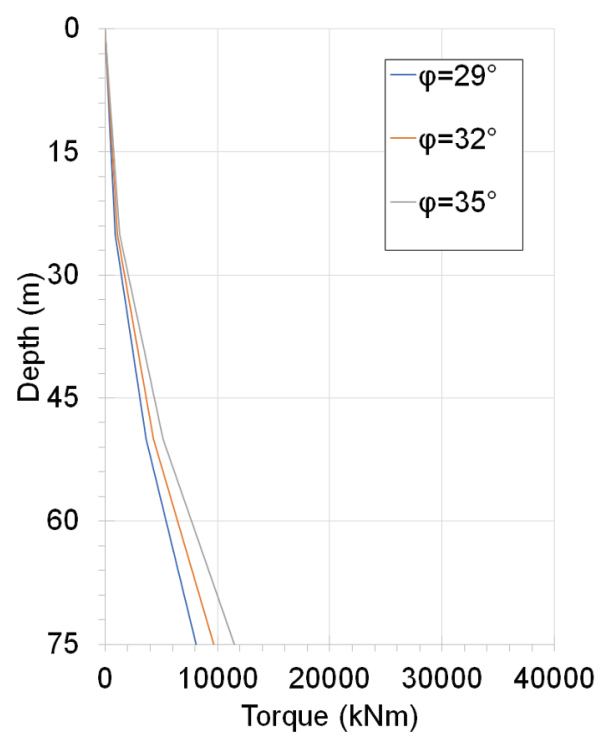

Fig. 2. Torque predictions for screw piles with different friction angle values for a depth of $75 \mathrm{~m}$ with the model of [25].

Tables 1 to 3 illustrates the predicted results of installation torque, installation power and the maximum ideal stress on the external ring of the pile $\left(\sigma_{i d, \max }\right)$. From this table it could be seen that the results of torque estimated using the model of [26] is about 3 times the values obtained using the model of [25]. This difference occurred probably because the model of [26] used a coefficient of passive earth pressure of approximately 3 times the value used in [25].

\subsection{Models verification}

The three torque models used in this work provide very different results. However, there are no torque data found in literature on deep high capacity helical piles installed in saturated sand (offshore) to evaluate the models of [25, 26 and 29] for this particular condition. On the other hand, [33] installed high capacity helical piles in sand at shallower depths $(5.75 \mathrm{~m}, 6.1 \mathrm{~m}$ and 9.5 $\mathrm{m})$ and measured the final installation torque. In [33], single-helix piles were installed in medium dense to very dense sand with friction angle of $35^{\circ}$, in a site with the ground water level about $3.6 \mathrm{~m}$ below ground surface. Data are shown in Tab. 4.

The torque results of three single-helix piles (with helix pitch of $152 \mathrm{~mm}$ ) measured in [33] are compared with the predicted results using models of [25], [26], and [29]. The comparison is shown in Table 4 and in Fig.5.

In [33], holes with size less than or equal to shaft size were predrilled before helical pile installation (predrilling depth inferior to helix depth), and soil plug inside the piles were formed. The effect of soil plug and predrilling were not considered in the predictions shown in Table 4. The calculated results presented in this table indicate that the models of [25] and [29] provided torque values of similar magnitude to the measured results in [33].

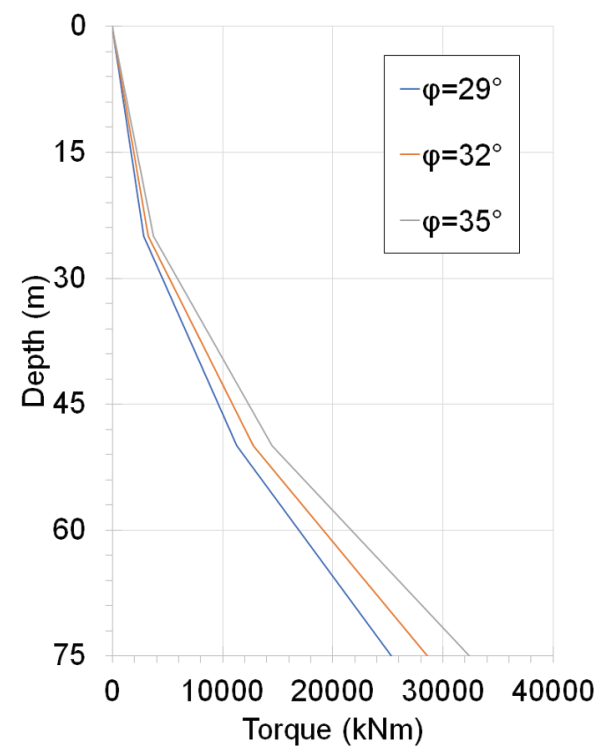

Fig. 3. Torque predictions for screw piles with different friction angle values for a depth of $75 \mathrm{~m}$ with the model of [26]

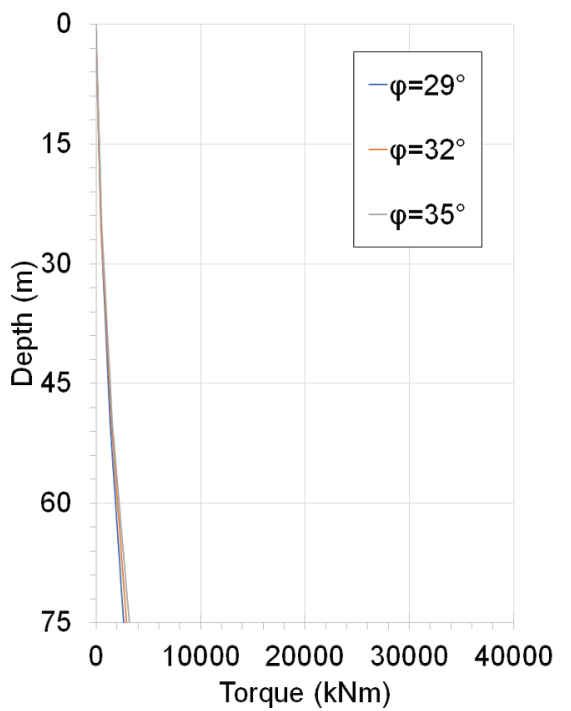

Fig. 4. Torque predictions for screw piles with different friction angle values for a depth of $75 \mathrm{~m}$ with the model of [29]. 
Table 1. Summary of the parametric analysis for the model of [25] down to $75 \mathrm{~m}$ depth

\begin{tabular}{|c|c|c|c|c|c|}
\hline \multicolumn{6}{|c|}{ Ghaly and Hanna [25] } \\
\hline $\begin{array}{c}\phi \\
\left({ }^{\circ}\right)\end{array}$ & $\begin{array}{c}\mathrm{H} \\
(\mathrm{m})\end{array}$ & $\begin{array}{l}\text { Vertical } \\
\text { (MN) }\end{array}$ & $\begin{array}{l}\text { Torque } \\
(\mathrm{MNm})\end{array}$ & $\begin{array}{l}\text { Power } \\
\text { (MW) }\end{array}$ & $\begin{array}{l}\sigma_{i d, \max } \\
(\mathrm{MPa})\end{array}$ \\
\hline 29 & \multirow{3}{*}{25} & 3.9 & 0.9 & 2.2 & 413.4 \\
\hline 32 & & 4.7 & 1.1 & 2.6 & 493.7 \\
\hline 35 & & 5.6 & 1.3 & 3.1 & 589.3 \\
\hline 29 & \multirow{3}{*}{50} & 15.3 & 3.6 & 8.6 & 1607.9 \\
\hline 32 & & 18.23 & 4.3 & 10.3 & 1924.0 \\
\hline 35 & & 21.8 & 5.1 & 12.2 & 2300.4 \\
\hline 29 & \multirow{3}{*}{75} & 34.0 & 8.10 & 19.2 & 3583.4 \\
\hline 32 & & 40.7 & 9.6 & 22.9 & 4290.8 \\
\hline 35 & & 48.7 & 11.5 & 27.3 & 5133.4 \\
\hline
\end{tabular}

Table 2. Summary of the parametric analysis for the model of [26] down to $75 \mathrm{~m}$ depth

\begin{tabular}{|c|c|c|c|c|c|}
\hline \multicolumn{6}{|c|}{ Sakr [26] } \\
\hline $\begin{array}{c}\phi \\
\left(^{\circ}\right)\end{array}$ & $\begin{array}{c}\mathrm{H} \\
(\mathrm{m})\end{array}$ & $\begin{array}{c}\text { Vertical } \\
(\mathrm{MN})\end{array}$ & $\begin{array}{l}\text { Torque } \\
\text { (MNm) }\end{array}$ & $\begin{array}{l}\text { Power } \\
\text { (MW) }\end{array}$ & $\begin{array}{l}\sigma_{i d, \max } \\
(\mathrm{MPa})\end{array}$ \\
\hline 29 & \multirow{3}{*}{25} & 3.9 & 2.9 & 6.3 & 482.6 \\
\hline 32 & & 4.7 & 3.3 & 7.1 & 567.6 \\
\hline 35 & & 5.6 & 3.7 & 8.1 & 668.9 \\
\hline 29 & \multirow{3}{*}{50} & 15.3 & 11.3 & 24.7 & 1883.7 \\
\hline 32 & & 18.3 & 12.8 & 28.0 & 2217.4 \\
\hline 35 & & 21.8 & 14.5 & 31.9 & 2614.9 \\
\hline 29 & \multirow{3}{*}{75} & 34.0 & 25.3 & 55.3 & 4203.4 \\
\hline 32 & & 40.7 & 28.6 & 62.6 & 4949.3 \\
\hline 35 & & 48.7 & 32.5 & 71.2 & 5838. \\
\hline
\end{tabular}

Table 3. Summary of the parametric analysis for the model of [29] down to $75 \mathrm{~m}$ depth

\begin{tabular}{|c|c|c|c|c|c|}
\hline \multicolumn{6}{|c|}{ Spagnoli et al. [29] } \\
\hline $\begin{array}{c}\phi \\
\left(^{\circ}\right) \\
\end{array}$ & $\begin{array}{c}\mathrm{H} \\
(\mathrm{m})\end{array}$ & $\begin{array}{c}\text { Vertical } \\
(\mathrm{MN})\end{array}$ & $\begin{array}{l}\text { Torque } \\
(\mathrm{MNm})\end{array}$ & $\begin{array}{l}\text { Power } \\
\text { (MW) }\end{array}$ & $\begin{array}{l}\sigma_{i d, \max } \\
(\mathrm{MPa})\end{array}$ \\
\hline 29 & \multirow{3}{*}{25} & 3.9 & 0.4 & 1.2 & 406.9 \\
\hline 32 & & 4.7 & 0.5 & 1.3 & 485.3 \\
\hline 35 & & 5.6 & 0.5 & 1.4 & 578.9 \\
\hline 29 & \multirow{3}{*}{50} & 15.3 & 1.3 & 3.8 & 1578.2 \\
\hline 32 & & 18.3 & 1.4 & 4.2 & 1887.7 \\
\hline 35 & & 21.8 & 1.6 & 4.7 & 2256.3 \\
\hline 29 & \multirow{3}{*}{75} & 34.0 & 2.6 & 7.8 & 3514.6 \\
\hline 32 & & 40.7 & 2.9 & 8.7 & 4207.3 \\
\hline 35 & & 48.7 & 3.2 & 9.9 & 5032.5 \\
\hline
\end{tabular}

Table 4. Comparison between measured torque in [33] and calculated results using models of [25, 26 and 29].

\begin{tabular}{|c|c|c|c|c|c|c|}
\hline $\begin{array}{c}\text { Pile } \\
\text { ID }\end{array}$ & $\begin{array}{c}\mathrm{D} / \mathrm{d} \\
(\mathrm{mm})\end{array}$ & $\begin{array}{c}\text { Pile } \\
\text { depth } \\
(\mathrm{m})\end{array}$ & $\begin{array}{c}\text { Torque } \\
\text { meas. } \\
(\mathrm{kNm})\end{array}$ & $\begin{array}{c}\text { Model } \\
{[25]} \\
(\mathrm{kNm})\end{array}$ & $\begin{array}{c}\text { Model } \\
{[26]} \\
(\mathrm{kNm})\end{array}$ & $\begin{array}{c}\text { Model } \\
{[29]} \\
(\mathrm{kNm})\end{array}$ \\
\hline St1 & $\begin{array}{c}762 / \\
324\end{array}$ & 9.5 & 211.5 & 325.5 & 900.3 & 262.5 \\
\hline $\begin{array}{c}\text { St2 } \\
0\end{array}$ & $\begin{array}{c}914 / \\
406\end{array}$ & 6.1 & 338.3 & 248.4 & 674.4 & 302.2 \\
\hline $\begin{array}{c}\text { St2 } \\
2\end{array}$ & $\begin{array}{c}1016 / \\
508\end{array}$ & 5.75 & 338.3 & 303.2 & 820.2 & 383.4 \\
\hline
\end{tabular}

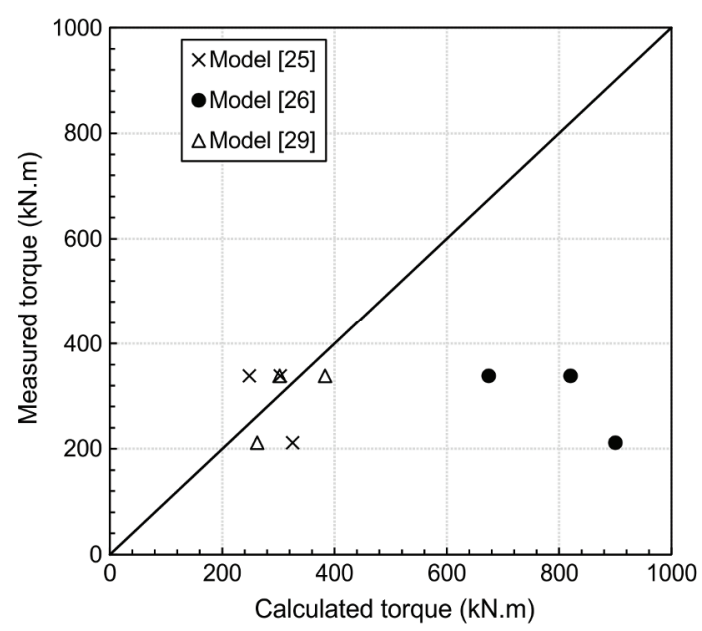

Fig. 5. Comparison between measured and calculated torque results using models of [25, 26 and 29].

\section{Conclusions}

The installation torque is an important element for assessing the feasibility of offshore helical piles Three torque models have been used considering a fixed pile geometry and increasing friction angle of the sands for different installation depths. It is shown that increasing the friction angle and the depth, torque increases as well. For the model [26] torque is three times higher than the model [25] and about 10 times higher considering the model of [29]. However, a comparison between measured and predicted results of installation torque of helical piles with embedment depths from $5.8 \mathrm{~m}$ to $9.5 \mathrm{~m}$, showed that the models [25] and [29] provided similar results of torque, closed to the measured values, and the model [26] overestimated the values of torque. The difference between the results provided by the models [25] and [26] is probably due to the difference of the coefficient of passive earth pressure adopted. An important point was observed: the assumed yield strength of a steel of $250 \mathrm{MPa}$, for piles deeper than $25 \mathrm{~m}$, seems to be not enough. This means that likely more piles for each leg are required when deep piles are needed.

\section{References}

1. H.G. Poulos, Marine Geotechnics (Spon Press, 1988). 
2. M. Randolph, S. Gourvenec, Offshore Geotechnical Engineering (CRC Press, 2011).

3. G. Spagnoli, P. Doherty, D. Bellato, L. Weixler, Latest technological developments in offshore deep mixing for piled Oil and Gas platforms. ASME 2014 33rd International Conference on Ocean, Offshore and Arctic Engineering, June 8-13, 2014, San Francisco, California, USA. Volume 3, V003T10A001, https://doi.org/10.1115/OMAE2014-23045.

4. B.C. Chattopadhyay, P.J. Pise, J. Geotech. Eng. 112, 9 (1986)

5. K. Gavin, D. Igoe, P. Doherty, P.I. Civil Eng. Geotec. 164, 4 (2011),

6. E. Oguz, D. Clelland, A.H. Day, A. Incecik, J. López Amate, G. Sanchez, G. Gonzalez Almeria, Ocean Eng. 147 (2018)

7. B. Byrne, G. Houlsby, Philos. Trans. Royal Soc. A, 373 (2015)

8. C. Davidson, T. Al-Baghdadi, M.J. Brown, J. Knappett, A. Brennan, C.E. Augarde, L. Wang, W.M. Coombs, D. Richards, A. Blake, J. Ball, Centrifuge modelling of screw piles for offshore wind energy foundations. Physical modelling in geotechnics: Proceedings of the 9th International Conference on Physical Modelling in Geotechnics (ICPMG 2018), July 17-20, 2018, London, United Kingdom. Volume 1. CRC Press, Boca Raton, 695700.

9. B. Cerfontaine, J.A. Knappett, M.J. Brown, C. Davidson, Y. Sharif, Screw pile design optimisation under tension in sand. Proceedings of the XVII European Conference on Soil Mechanics and Geotechnical Engineering, Rykjavik 1-6 September 2019, doi: 10.32075/17ECSMGE-2019-0696.

10. G. Spagnoli, Mar. Georesour. Geotech. 35, 4 (2017)

11. Arup Geotechnics, Design of screw piles (2005)

12. G. Spagnoli, Soil Mech. Found. Eng. 50, 3 (2013)

13. C.H.C. Tsuha, N. Aoki, Can. Geotech. J. 47, 6 (2010)

14. G. Spagnoli, K. Gavin, Helical Piles as a Novel Foundation System for Offshore Piled Facilities. Proceedings of the Abu Dhabi International Petroleum Exhibition and Conference, 9-12 November, Abu Dhabi, UAE, https://doi.org/10.2118/177604-MS (2015)

15. G. Spagnoli, K. Gavin, C. Brangan, In situ and laboratory tests in dense sand investigating the helix-to-shaft ratio of helical piles as a novel offshore foundation system. Frontiers in Offshore Geotechnics III, Meyer, V. (Editor), Taylor \& Francis Group, London, 643-648 (2015)

16. A.M.A. Fateh, A. Eslami, A. Fahimifar, Mar. Georesour. Geotech. 35, 2 (2017)

17. G. Spagnoli, C.H.C. Tsuha, Mar. Georesour. Geotech. 38, 9, (2020) https://doi.org/10.1080/1064119X.2020.1729905
18. B. Livneh, M.H.M. Naggar, Can. Geotech. J. 45, 8 (2008)

19. G. Spagnoli, C.H.C. Tsuha, P. Oreste, C.M. Mendez Solarte, J. Waterw. Port C.-ASCE 144, 6 (2018)

20. G. Spagnoli, C.H.C. Tsuha, P. Oreste, C.M. Mendez Solarte, DFI J 12, 3 (2019)

21. R.M. Hoyt, S.P. Clemence, Uplift Capacity of Helical Anchors in Soil. Proceedings of the 12th International Conference on Soil Mechanics and Foundation Engineering, Rio de Janeiro, Brazil (1989).

22. CFEM, Canadian Foundation Engineering Manual. 4th Edition. Canadian Geotechnical Society, Technical Committee on Foundations, BiTech Publishers Ltd (2006)

23. Z.Z. Mosquera, C.H.C. Tsuha, A.T. Beck, Serviceability performance evaluation of helical piles under uplift loading. J. Perfom. Constr. Fac. 30, 4 (2016)

24. M. Tadashi, F. Mikio, A study of end-bear capacity mechanism of steel spiral pile. Deep Foundation on Bored and Auger Piles, 161-166 (2009)

25. A. Ghaly, A. Hanna, Can. Geotech. J. 28, 3, (1991)

26. M. Sakr, J. Perfom. Constr. Fac. 29, 6 (2015)

27. K. Gavin, P. Doherty, A. Tolooiyan, Can. Geotech. 51, 11 (2014)

28. T. Al-Baghdadi, M.J. Brown, C. Davidson, J. Knappett, A. Brennan, L. Wang, W.M. Coombs, C.W. Augarde, D. Richards, A. Blake, CPT-based design procedure for installation torque prediction for screw piles installed in sand.', in Offshore site investigation and geotechnics: integrated geotechnologies - present and future: proceedings of the 8th international conference, held 12-14 September 2017 at the Royal Geographical Society, London. London: Society for Underwater Technology, pp. 346-353 (2017)

29. G. Spagnoli, C.M. Mendez Solarte, C.H.C. Tsuha, P. Oreste, Int. J. Geotech. Eng. 14, 5 (2020) https://doi.org/10.1080/19386362.2018.1452362

30. A.B. Chance. Guide to Model Specification CHANCE® Civil Construction: Helical Piles for Structural Support. Bulletin 01-0303. Shelton: Hubbell Inc. (2010)

31. B.M. Lehane, J.A. Schneider, X. Xu, The UWA-05 method for prediction of axial capacity of driven piles in sand. In Frontiers in Offshore Geotechnics. Edited by M. Cassidy and S. Gourvenec, Taylor \& Francis Group, London, 683-688 (2005)

32. G. Spagnoli, C.H.C. Tsuha, P. Oreste, P., C.M. Mendez Solarte. J. Waterway Port Coast 144, 6, (2018)

33. Sakr, M., Bartlett, F. High capacity helical piles-a new dimension for bridge foundations. In Proceedings of 8th international conference on short and medium span bridges, Niagara Falls, Canada. (2010). 